\title{
Impact of an educational programme on knowledge, beliefs, practices and expectations about care among adolescent glaucoma patients in Cairo
}

\author{
E.A. Mohamed, ' O.R. Bayoumi' and S.F. Draz'
}

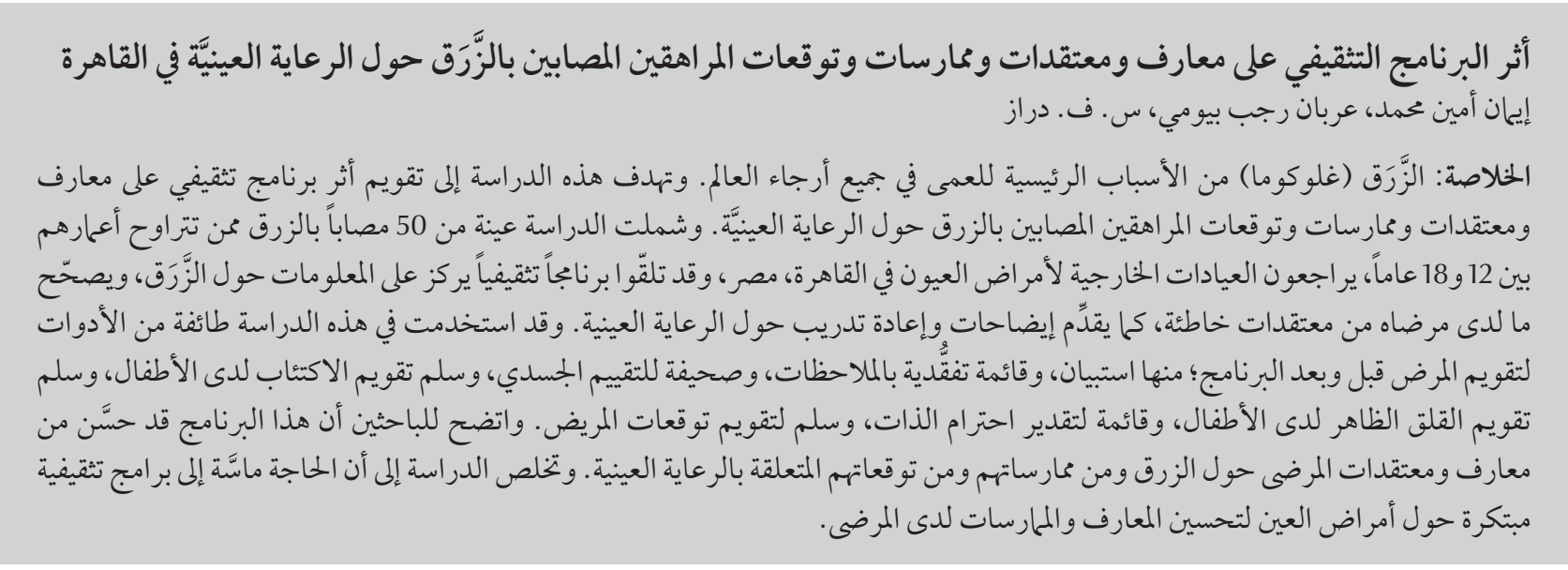

ABSTRACT Glaucoma is a leading cause of blindness worldwide. The aim of the current study was to evaluate the impact of an educational programme on knowledge, beliefs, practices and expectations towards glaucoma and eye care among adolescent patients with glaucoma. A purposive sample of 50 patients with glaucoma aged 12-18 years, attending ophthalmology outpatient clinics in Cairo, Egypt, were given an educational programme focusing on information about glaucoma, correcting patients' incorrect beliefs and expectations, and demonstrations and retraining about eye care. A range of tools was used to assess patients before and after the programme: questionnaire, observation checklist, physical assessment sheet, childrens' depression scale, children manifest anxiety scale, self-esteem inventory and patients' expectations scale. The programme significantly improved patients' knowledge and beliefs about glaucoma and their practices and expectations concerning eye care. Innovative educational programmes about eye diseases are needed to improve patients' knowledge and practices.

Impact d'un programme éducatif sur les connaissances, les croyances, les pratiques et les attentes en termes de soins de patients adolescents atteints d'un glaucome au Caire

RÉSUMÉ Le glaucome est une cause majeure de cécité dans le monde. La présente étude avait pour objectif d'évaluer l'impact d'un programme éducatif sur les connaissances, les croyances, les pratiques et les attentes en termes de soins oculaires d'adolescents atteints d'un glaucome. Un échantillon choisi à dessein de 50 patients souffrant de glaucome, âgés de 12 à 18 ans, consultant un centre de soins externes en ophtalmologie au Caire (Égypte) a bénéficié d'un programme éducatif sur cette maladie, visant à corriger leurs idées fausses et leurs attentes, et comportant des démonstrations et des formations de perfectionnement sur les soins oculaires. Une série d’outils a été utilisée pour évaluer les connaissances des adolescents avant et après le programme : un questionnaire, une liste de contrôle des observations, une fiche d'évaluation physique, une échelle de mesure de la dépression chez les enfants, une échelle d'anxiété manifeste pour enfants, l'inventaire de l'estime de soi et une échelle de mesure des attentes des patients. Le programme a beaucoup amélioré les connaissances et les croyances de ces jeunes patients sur le glaucome ainsi que leurs pratiques et leurs attentes dans le domaine des soins oculaires. Des programmes éducatifs innovants sur les affections oculaires sont nécessaires pour accroître le savoir et les pratiques des patients. 


\section{Introduction}

Glaucoma is a group of eye diseases characterized by progressive loss of visual field due to damage to the optic nerve fibres [1]. Congenital and secondary glaucoma affects more than 3 million people in the Eastern Mediterranean region, 500000 of them children and adolescents [2].

While glaucoma is not preventable, early detection and treatment can help to avoid serious damage to a person's vision [3]. Wilson et al. confirmed that the aim of glaucoma treatment is to slow the rate of field loss by reducing intraocular pressure [4]. Some simple methods of self-care are available to patients with glaucoma. For example, therapeutic nutrition such as foods rich in antioxidants (lutein and zeaxanthin), vitamins (C, E and $\mathrm{A}$ ) and minerals (zinc and copper), and eye compresses and eye exercises are natural ways to lower intraocular pressure, improve blood flow to the retina and optic nerve, preserve patients' vision and limit glaucoma-related vision loss $[5,6]$. A nursing-based educational programme can address these issues by improving patients' awareness about their illness and hence compliance with therapy, as well as encouraging natural approaches to glaucoma care $[7,8]$.

Patients' expectations have begun to play an increasingly important role in medical and nursing care and quality assessment. Patients with glaucoma were shown to have various expectations depending on their age, socioeconomic status and severity of their conditions [9]. Meeting patients' expectations has been shown to be associated with greater patient satisfaction and hence increased compliance with medical and nursing recommendations [10].

There is limited evidence in the literature about paediatric patients' knowledge, attitudes and expectations. Yet glaucoma care for young people presents difficult clinical challenges and, even when glaucoma is treated appropriately, blindness can result. In Egypt, more than half a million children and adolescents are estimated to be affected by glaucoma $[11,12]$. The aim of the current study was to evaluate the impact of an educational programme on the knowledge, practices and expectations towards glaucoma and eye care among adolescent patients with glaucoma.

\section{Methods}

A quasi-experimental design was utilized.

\section{Setting and sample}

The study was conducted at the ophthalmology outpatient clinics in Ain Shams University hospital, New Children's hospital (Japanese hospital) and Research Institute of Ophthalmology affiliated to the University of Cairo, ElMataria teaching hospital affiliated to the Egyptian general health organization for teaching hospitals.

A purposive sample consisting of 50 adolescents (age range 12-18 yeas old) were enrolled according to the following inclusion criteria: having congenital or secondary glaucoma, intraocular pressure $\leq 21 \mathrm{mmHg}$, characteristic pattern of glaucomatous visual field changes and previous diseases such as type 1 and 2 diabetes mellitus, epilepsy, juvenile arthritis, nephrotic syndrome and taking corticosteroid medications.

\section{Data collection}

\section{Tools}

The following data collection tools were used:

- Review of each patient's clinical records to document ocular symptoms and complications. The data collected included: corrected visual acuity of both eyes, visual field, dilated eye examination results, tonometry results and ultrasound wave results to detect signs of retina and optic nerve damage, thickening of the cornea and other eye diseases.
- Structured questionnaire to assess patients' knowledge about glaucoma. It was designed by the researchers after reviewing the relevant literature. First, the background sociodemographic and clinical characteristics of the respondents were recorded: age, sex, level of education, residence, previous diagnosis, present diagnosis and duration of illness. The knowledge questions assessed knowledge about glaucoma (definition, causes, clinical manifestations and management); incorrect beliefs about risk factors for glaucoma (diet, sleeping pattern, traumatic stress and play); and incorrect beliefs and attitudes towards glaucoma (the effect of nightmares on intraocular pressure, the effectiveness of management and follow up and their feelings about the future). There were 40 questions with open- and close-ended responses and the questionnaire took about 15 minutes to be filled by the researcher with each patient. According to patients' responses, their knowledge was classified as either satisfactory (score $\geq 50 \%$ correct) or unsatisfactory (score $<50 \%$ correct). Responses to belief questions were scored as agree (score 0 ), uncertain (score 1) and disagree (score 2), with total scores converted into percentages and classified as either satisfactory $(<50 \%)$ or unsatisfactory $(\geq 50 \%)$.

- Observation checklist to assess patients' practices regarding eye care. Adapted from Margret [13] and Watkinson and Seewoodhaky [14], the checklist included: eyedrop instillation (handling, storage and administration), eye ointment application, and eye exercises and eye compresses. Each patient was observed and evaluated and the observation checklist was filled by the researchers. There were 10 procedures, scored 1 point for each step done correctly with a total score of 10. Patients' practices were catego- 
rized as either done correctly (score $7-10$ ) or not done correctly (score $<7)$.

- Physical and social assessment [15] to assess difficulties with activities of daily life. The scale had 24 questions concerning: walking, going up or down stairs, talking, reading and writing, school attendance, and shopping. The total score was 24 . Scoring was as follows: no problems (score 0 ); mild problems (score 1-8); moderate problems (score 9-16); severe problems (score 17-24).

- Psychometric assessment of the psychological problems of patients. This questionnaire used the following 3 scales:

- Children manifest anxiety scale $[16,17]$ assessed the degree of severity of anxiety symptoms in the following domains: somatic, emotional, physiological, mental, motor, and social. It consisted of 36 statements to which the patient answered no (score 0 ) or yes (score 1). The severity of anxiety symptoms was graded as: no anxiety (score 0 ); mild anxiety (score $1-12$ ); moderate anxiety (score 13-24); severe anxiety (score 25-36).

- Children depression inventory [18] assessed the degree of severity of depressive symptoms: grief, failure feelings, wrong behaviour, disturbance in emotion, sleep disorders, social problems and low school performance. It consisted of 27 questions, each with 3 statements scored from $0-2$. The total severity of depressive symptoms was graded as: mild depression (score 0-18); moderate depression (score 19-36); severe depression (score 37-54).

- Self-esteem inventory [19] measured patients' self-esteem and evaluated attitudes towards self in terms of social, academic, family, and personal areas of experienc- es. It consisted of 24 statements, each statement answered by the patient as like me (1 point) or unlike me (0 points). The total scores were graded as: low selfesteem (score 0-8); moderate self-esteem (score 8-16); high self-esteem (score 16-24).

- Patients' expectations scale [20], which was modified by the researchers to assess potential effects of disease on patients' expectations. The scale classified the 17 expectations areas articulated by patients into 6 groups: communication, interpersonal manner, ophthalmologists and nurses' skills, examination and testing, logistics of health services, and other. The patients' responses were classified as: satisfactory expectations score (score 11-17); unsatisfactory expectations (score $<11)$.

\section{Testing and validity}

A pilot study was done on 5 patients with glaucoma in order to test the study tools in terms of clarity, validity and reliability of content and to make any necessary modifications. The same results were achieved on 2 successive trials. On the other hand, the pilot study demonstrated a wide variation between patients in terms of knowledge and eye care practices and the need for a better nursing programme to tackle these problems. Patients involved in the pilot study were later excluded from the study sample.

Face and content validity were ascertained by a group of experts including medical and nursing personnel in ophthalmology clinics. Their opinions were elicited regarding the format, content consistency and scoring system of the tools.

\section{Ethical considerations}

Approval was obtained from medical and nursing administrators of the study settings and the glaucoma patients and their companions. A clear explanation of the nature of the study was offered to patients and anonymity was assured. Patients were allowed to withdraw from the study whenever they wished.

\section{Fieldwork}

The fieldwork was carried out over 10 months from December 2008 to September 2009. To obtain the required number of patients, the researchers went to ophthalmology outpatient clinics twice a week from 09.00 to 12.30 by rotation in each previously sitting. Each patient was assessed individually and the researchers completed the abovementioned tools during the interview, both before and after the patient had participated in the educational intervention (pre- and post-programme).

\section{Intervention}

An educational programme was given to groups of patients with glaucoma; each group included 2 patients. The programme was designed based on a needs' assessment of patients and included 5 sessions for theory and 10 sessions for practices performed by the researchers, with each patient trained individually in practices. The sessions were repeated according to each patient's medical condition and level of understanding. The programme sessions started with an explanation of the aims of the study and its expected outcomes and a description of the programme and its sessions. The content of the programme included information about glaucoma, with the emphasis on correcting patients' incorrect beliefs and expectations, and demonstrations and retraining of patients about eye care in terms of eyedrop handling, storage and installation, ointment application, eye compresses (hot and cold), and eye exercises. Different teaching strategies were used in simple, Arabic language.

\section{Statistical analysis}

The collected data were tabulated, analysed and subjected to statistical tests. The data were presented as frequencies, percentages and mean and standard 
deviation (SD). The chi-squared and $t$-tests were used for analysis.

\section{Results}

The 50 patients enrolled in this study had a mean age of 15.9 (SD 2.4) years. As shown in Table 1,20\% had congenital glaucoma and $80 \%$ had secondary glaucoma, while $30 \%$ of them had a history of diabetes mellitus. The mean duration of illness was 6.6 (SD 2.0) years; $46 \%$ of patients had suffered glaucoma for 3 or more years.

\section{Patients' knowledge, beliefs and attitudes}

The proportion of patients with satisfactory knowledge scores ( $\geq 50 \%$ correct) was very low before implementation of the educational programme (12\%). Post-programme, however, this percentage increased significantly to $96 \%$ $\left(\chi^{2}=70.9, P<0.001\right)($ Table 2$)$.

Pre-programme, patients had many misconceptions about glaucoma and poor attitudes towards their future health, all of which improved after the programme. Diet as a factor inducing glaucoma was reported by all patients (100\%) pre-programme but only 6\% post-programme $\left(\chi^{2}=88.7, P<0.001\right)$. While all the patients $(100 \%)$ believed that management and follow up of their

\begin{tabular}{|c|c|c|}
\hline Variables & No. & $\%$ \\
\hline \multicolumn{3}{|l|}{ Age (years) $^{a}$} \\
\hline $12-14$ & 23 & 46 \\
\hline $15-17$ & 11 & 22 \\
\hline 18 & 16 & 32 \\
\hline \multicolumn{3}{|l|}{ Sex } \\
\hline Male & 30 & 60 \\
\hline Female & 20 & 40 \\
\hline \multicolumn{3}{|l|}{ Educational level } \\
\hline Illiterate & 27 & 54 \\
\hline Preparatory school & 11 & 22 \\
\hline Secondary school & 12 & 24 \\
\hline \multicolumn{3}{|l|}{ Residence } \\
\hline Rural & 29 & 58 \\
\hline Urban & 21 & 42 \\
\hline \multicolumn{3}{|l|}{ Previous diagnosis } \\
\hline Juvenile diabetes & 15 & 30 \\
\hline Nephrotic syndrome & 13 & 26 \\
\hline Juvenile arthritis & 12 & 24 \\
\hline \multicolumn{3}{|l|}{ Present diagnosis } \\
\hline Congenital glaucoma & 10 & 20 \\
\hline Secondary glaucoma & 40 & 80 \\
\hline \multicolumn{3}{|l|}{ Duration of illness (years) } \\
\hline $3-$ & 23 & 46 \\
\hline $6-$ & 11 & 22 \\
\hline 9- & 16 & 32 \\
\hline
\end{tabular}

${ }^{a}$ Mean age $($ standard deviation $)=15.9(2.4)$ years .

${ }^{b}$ Mean duration of illness (standard deviation $)=6.6(2.0)$ years.

\begin{tabular}{|c|c|c|c|c|c|c|}
\hline \multirow[t]{2}{*}{ Items } & \multicolumn{2}{|c|}{ Pre-programme } & \multicolumn{2}{|c|}{ Post-programme } & \multirow[t]{2}{*}{$\chi^{2}$-value } & \multirow[t]{2}{*}{$P$-value } \\
\hline & No. & $\%$ & No. & $\%$ & & \\
\hline Correct knowledge about disease & 6 & 12 & 48 & 96 & 70.9 & $<0.001$ \\
\hline \multicolumn{7}{|l|}{ Incorrect beliefs about factors causing glaucoma } \\
\hline Diet & 50 & 100 & 3 & 6 & 88.7 & $<0.001$ \\
\hline Sleeping patterns & 27 & 54 & 2 & 4 & 28.1 & $<0.001$ \\
\hline Traumatic stress & 20 & 40 & 3 & 6 & 29.2 & $<0.001$ \\
\hline Play & 29 & 58 & 4 & 8 & 28.3 & $<0.001$ \\
\hline Nightmares & 30 & 60 & 5 & 10 & 72.7 & $<0.001$ \\
\hline \multicolumn{7}{|l|}{ Poor attitudes towards glaucoma care and future health } \\
\hline Believe management and follow-up is ineffective & 50 & 100 & 4 & 8 & 86.3 & $<0.001$ \\
\hline Have feelings of hopelessness about future life & 50 & 100 & 3 & 6 & 88.7 & $<0.001$ \\
\hline Believe future occupational chances are impaired & 30 & 60 & 5 & 10 & 27.9 & $<0.001$ \\
\hline
\end{tabular}

Responses were not mutually exclusive. 


\begin{tabular}{|c|c|c|c|c|c|c|}
\hline \multirow[t]{2}{*}{ Practices } & \multicolumn{2}{|c|}{ Pre-programme } & \multicolumn{2}{|c|}{ Post- programme } & \multirow[t]{2}{*}{$x^{2}$-value } & \multirow[t]{2}{*}{$P$-value } \\
\hline & No. & $\%$ & No. & $\%$ & & \\
\hline Eye drops instillation & 3 & 6 & 47 & 94 & 34.1 & $<0.001$ \\
\hline Eye ointment application & 4 & 8 & 46 & 92 & 31.7 & $<0.001$ \\
\hline Eye exercises & 0 & 0 & 32 & 64 & 35.2 & $<0.001$ \\
\hline Eye compresses & 3 & 6 & 50 & 100 & 86.2 & $<0.001$ \\
\hline
\end{tabular}

care were ineffective and felt a loss of hope in their future, post-programme these percentages decreased significantly to $8 \%\left(\chi^{2}=86.3, P<0.001\right)$ and $6 \%\left(\chi^{2}=88.7, P<0.001\right)$ respectively.

\section{Patients' eye care practices}

Table 3 shows that none of the patients reported performing eye exercises preprogramme, while around two-thirds (64\%) were performing this procedure post-programme $\left(\chi^{2}=35.2, P<0.001\right)$. Similarly, all patients (100\%) were using eye compresses post-programme, a highly significant increase on the pre-programme rate $(6 \%)\left(\chi^{2}=86.2\right.$, $P<0.001)$.

\section{Patients' physical and social problems}

Table 4 shows that most of the patients (94\%) reported difficulties with attending school pre-programme, while $12 \%$ of the patients only had this problem post-programme $\left(\chi^{2}=31.9, P<0.05\right)$. Also, $66 \%$ of the patients had difficulties in walking pre-programme compared with only $20 \%$ post-programme $\left(\chi^{2}=21.6, P<0.05\right)$.

\section{Patients' psychological problems}

Regarding patients' psychological problems, the percentage suffering severe depression fell from $26 \%$ pre-programme to $8 \%$ post-programme $\left(\chi^{2}=2.4, P\right.$ $<0.05$ ) (Table 5). Mean depression scores fell from 1.98 (SD 0.7) to 1.64 (SD 0.7). The rate of low self-esteem fell from $90 \%$ to $22 \%$ post-programme $\left(\chi^{2}=10.0, P<0.001\right)$, with mean selfesteem scores rising from 1.1 (SD 0.3) to 1.8 (SD 0.4).

\section{Patients' expectations}

The results of the assessment of patients' expectations of their care showed that a minority of patients (4\%) reported listening and addressing concerns pre-programme, which rose to $72 \%$ post-programme $\left(\chi^{2}=59.7, P<\right.$ 0.001 ) (Table 6). In addition, few patients pre-programme ( $8 \%)$ stated that competence was important for ophthalmologists and nurses, whereas postprogramme $100 \%$ of them believed that competence was important $\left(\chi^{2}=41.3\right.$, $P<0.001)$. Pre-programme, only $6 \%$ of patients stated that examination and testing were essential in their expectations, whereas all of them (100\%) had these expectations post-programme $\left(\chi^{2}=88.6, P<0.001\right)$.

\section{Discussion}

Congenital and secondary glaucoma, although sometimes difficult to detect, has a traumatic impact on patients' behavioural and psychosocial development. In the present study we focused on adolescent patients (aged from 12 to 18 years, half aged < 15 years) and assessed their knowledge and practices towards glaucoma and eye care and determined their expectations of care before and after an educational nursing programme about glaucoma for these patients.

Our study found that, before the educational programme, only $12 \%$ of this group of young people had satisfactory knowledge about glaucoma. This could be attributed to a lack of educational materials about glaucoma in Arabic language, lack of time for ophthalmologists and nurses to

\begin{tabular}{|c|c|c|c|c|c|c|}
\hline \multirow[t]{2}{*}{ Items } & \multicolumn{2}{|c|}{ Pre-programme } & \multicolumn{2}{|c|}{ Post- programme } & \multirow[t]{2}{*}{$\chi^{2}$-value } & \multirow[t]{2}{*}{$P$-value } \\
\hline & No. & $\%$ & No. & $\%$ & & \\
\hline Difficulty walking & 33 & 66 & 10 & 20 & 21.6 & $<0.001$ \\
\hline Difficulty going up or down stairs & 35 & 70 & 6 & 12 & 23.5 & $<0.001$ \\
\hline Difficulty talking & 13 & 26 & 6 & 12 & 7.6 & $<0.001$ \\
\hline Difficulty reading and writing & 33 & 66 & 4 & 8 & 24.5 & $<0.001$ \\
\hline Difficulty attending school & 47 & 94 & 6 & 12 & 31.3 & $<0.001$ \\
\hline Difficulty going shopping & 33 & 66 & 3 & 6 & 25.1 & $<0.001$ \\
\hline
\end{tabular}

Responses were not mutually exclusive. 


\begin{tabular}{|c|c|c|c|c|c|c|}
\hline \multirow[t]{2}{*}{ Items } & \multicolumn{2}{|c|}{ Pre-programme } & \multicolumn{2}{|c|}{ Post-programme } & \multirow[t]{2}{*}{$x^{2}$-value } & \multirow[t]{2}{*}{$P$-value } \\
\hline & No. & $\%$ & No. & $\%$ & & \\
\hline \multicolumn{7}{|l|}{ Anxiety } \\
\hline None & 0 & 0 & 21 & 42 & & \\
\hline Mild & 5 & 10 & 13 & 26 & 8.1 & $<0.05$ \\
\hline Moderate & 16 & 32 & 9 & 18 & & \\
\hline Severe & 29 & 58 & 7 & 14 & & \\
\hline Total mean (SD) score & \multicolumn{2}{|c|}{$2.50(0.7)$} & \multicolumn{2}{|c|}{$1.04(1.1)$} & & \\
\hline \multicolumn{7}{|l|}{ Depression } \\
\hline Mild & 14 & 28 & 31 & 62 & 2.4 & $<0.05$ \\
\hline Moderate & 23 & 46 & 15 & 30 & & \\
\hline Severe & 13 & 26 & 4 & 8 & & \\
\hline Total mean (SD) score & \multicolumn{2}{|c|}{$1.98(0.7)$} & \multicolumn{2}{|c|}{$1.64(0.7)$} & & \\
\hline \multicolumn{7}{|l|}{ Self-esteem } \\
\hline High & 5 & 10 & 39 & 78 & 10.0 & $<0.001$ \\
\hline Low & 45 & 90 & 11 & 22 & & \\
\hline Total mean (SD) score & \multicolumn{2}{|c|}{$1.10(0.3)$} & \multicolumn{2}{|c|}{$1.80(0.4)$} & & \\
\hline
\end{tabular}

$S D=$ standard deviation

provide patients with proper information, patients' low educational attainment (54\% were illiterate) and the limited training of ophthalmologists and nurses who are the main source of information for patients. After the programme, considerable improvement was detected in patients' knowledge, which could be attributed to the faceto-face theory and practice sessions given by the researchers together with posters and leaflets about glaucoma and eye care. In a similar study, Ahmad argued that children with glaucoma need detailed knowledge about the disease and eye care for successful prevention of visual impairment in the future [21].

Before the programme were some incorrect beliefs among patients about the factors inducing glaucoma. Pre-programme, all patients believed diet was a factor causing glaucoma. This confusion may be because many ophthalmologists recommend patients eat more spinach and other green leafy vegetables or to take supplements rich in antioxidants and vitamins $\mathrm{C}, \mathrm{E}$ and $\mathrm{A}$ and zinc to improve the blood supply to the optic nerve and slow the progression of visual impairment [22].
The current study found that all the patients pre-programme believed that management and follow up were ineffective and all had feelings of loss of hope in their future. This could be related to patients' awareness of the incurable nature of glaucoma. Postprogramme, however, the proportion of patients with negative attitudes and feelings decreased significantly. This may be attributed to better knowledge about glaucoma and to the support offered by the research team acting as educators. Murtadha also found that feelings of hopelessness about the future were a problem among patients with glaucoma [23]. For this reason, better knowledge about prevention and psychological support for glaucoma patients are clearly important.

Our analysis of patients' eye care practices showed that a majority of them did not practise topical glaucoma therapy correctly pre-programme. Glaucoma patients may not see well enough to know if the drops are centred over their eyes, leading to suboptimal treatment and a costly waste of medication. Health care providers may neglect to help patients to practise techniques of topical eye medication. Other authors have discussed the difficulties that glaucoma patients may have with administration of eyedrops $[24,25]$. In our study the educational programme significantly improved patients' eye care practices in terms of handling, storage and administration of topical therapy. Marsden and Shaw stated that proper use of glaucoma eyedrops can improve the medicine's effectiveness and reduce side-effects [25].

Another concern about eye care found in our study was that, pre-programme, none of the patients were performing eye exercises and very few were using eye compresses. Belal mentioned that eye exercises are a vital step for increasing eye relaxation, meditation and stress reduction and that compresses applied over the eyes (alternating 3 minutes with hot water and 1 minute with cold water) can be used to reduce intraocular pressure [5]. These eye practice issues were also documented by Danesh who argued that natural methods of eye care improve adequate blood supply to the optic nerve, improve the collagen structure of the eyes and drainage of aqueous humour thus leading to normalization of intraocular eye pressure [6]. Post-programme, our 


\begin{tabular}{|c|c|c|c|c|c|c|}
\hline \multirow[t]{2}{*}{ Items } & \multicolumn{2}{|c|}{ Pre-programme } & \multicolumn{2}{|c|}{ Post- programme } & \multirow[t]{2}{*}{$x^{2}$-value } & \multirow[t]{2}{*}{$P$-value } \\
\hline & No. & $\%$ & No. & $\%$ & & \\
\hline \multicolumn{7}{|l|}{ Communication } \\
\hline Discussion of family history & 6 & 12 & 30 & 60 & 59.7 & $<0.001$ \\
\hline Information about diagnosis and prognosis & 18 & 36 & 45 & 90 & & \\
\hline Information about medication & 19 & 38 & 43 & 86 & & \\
\hline Listening and addressing concerns & 2 & 4 & 36 & 72 & & \\
\hline \multicolumn{7}{|l|}{ Interpersonal manner } \\
\hline Personal connection & 4 & 8 & 47 & 94 & 54.3 & $<0.001$ \\
\hline Professionalism & 6 & 12 & 43 & 86 & & \\
\hline Courtesy & 6 & 12 & 42 & 84 & & \\
\hline Encouragement & 5 & 10 & 40 & 80 & & \\
\hline Patience & 9 & 18 & 45 & 90 & & \\
\hline \multicolumn{7}{|l|}{ Ophthalmologist and nurses'skills } \\
\hline Competence & 4 & 8 & 50 & 100 & 41.3 & $<0.001$ \\
\hline Health outcomes & 3 & 6 & 48 & 96 & & \\
\hline Access to advances in eye care & 2 & 4 & 47 & 94 & & \\
\hline Examination and testing & 3 & 6 & 50 & 100 & 88.6 & $<0.001$ \\
\hline \multicolumn{7}{|l|}{ Health service logistics } \\
\hline Waiting time & 4 & 8 & 37 & 74 & 46.6 & $<0.001$ \\
\hline Coordination of care & 3 & 6 & 42 & 84 & & \\
\hline Appointment access & 2 & 4 & 30 & 60 & & \\
\hline \multicolumn{7}{|l|}{ Other } \\
\hline Time with physicians & 5 & 10 & 40 & 80 & 4.9 & $<0.001$ \\
\hline Referral & 0 & 0 & 42 & 84 & & \\
\hline
\end{tabular}

Responses were not mutually exclusive.

results showed that there were significant improvements in the proportion of patients' reporting good eye care practices. Clearly patients need health education to increase their awareness about the importance of eye care to reduce the risk of visual impairment.

Our study findings also highlighted adolescent glaucoma patients' physical and social problems. Pre-programme, most patients were having difficulty in attending school and in walking and almost two-thirds had difficulties reading and writing. Visual impairment that accompanies glaucoma may lead to social and psychological difficulties [26]. Postprogramme, only $12 \%$ of patients reported difficulty in attendance of school. Glaucoma patients may require special schooling in order to maximize their educational achievements and in our case the researchers collaborated with schools about suitable arrangements.
In the initial stages of glaucoma patients may have difficulty recognizing stairs, reading fare charts and outdoor activities [27]. Eldar argued that parents should work closely with school staff and the educational system to ensure that the needs of children with glaucoma are met [28].

The present study found a high prevalence of psychological problems among adolescents with glaucoma; pre-programme, nearly half of patients had moderate depression, more than one-quarter had severe depression and $90 \%$ had low self-esteem. This could be attributed to emotional trauma in patients who were poorly adapted to their visual impairment. Thompson stated that children with glaucoma will show signs of anxiety and depression and feelings of low self-esteem [29]. Also they lose interest in activities that they used to enjoy before the development of glaucoma and this leads to a feeling of dejection and failure. After the educational programme, the young peoples' scores on the psychometric assessments were significantly improved in all domains.

Communication between glaucoma patients and the health care team (ophthalmologists and nurses) is crucial for successful coping with multiple outpatient clinic visits. The current study found that in the area of communication very few of our patients had expectations of carers' listening and addressing their concerns. Post-programme there was a significant improvement in patients' expectations. This could be due to the researchers helping patients to cope by listening and providing support during discussions about diagnosis and treatment with the ophthalmologist. Marple et al. argued that ophthalmologists and nurses should use every opportunity 
that arises for listening and talking to patients and helping them to cope with their disease both physically and psychologically [30].

Post-programme, the patients' highest expectations were in examination and testing and competence of ophthalmologist and nurses (100\% of patients expected these). Dondona et al. demonstrated that ophthalmologists' behaviours (examination and testing) were significantly influenced by their assumptions about patients' expectations and that ophthalmologists often do not correctly assess patients' expectations [31]. Increasing patients' expectations is likely to offer opportunities to improve the quality of eye care in the outpatient clinics. Dawn et al. found that eye care professionals vary in their training and experience [9]. Diagnosis, treatment and care require special attention and knowledge; glaucoma requires lifelong follow up of visual field changes with the goal of preservation of vision, the optic nerve needs to be regularly examined and documented and eye care providers need to keep upto-date with new methods of glaucoma treatment.

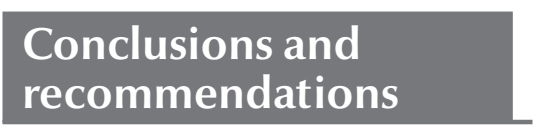

The educational nursing programme was effective in improving patients' knowledge and correcting their eye care practices. Post-programme, patients expressed a wide variety of expectations regarding to their glaucoma and eye care which might have implications for patients' satisfaction and the delivery of eye care. Clearly the management of children and adolescents with glaucoma requires a collaborative effort between the health care team, patients' families and schoolteachers. Innovative educational programme are needed to improve the knowledge and attitudes of young glaucoma patients and their parents. Further study is needed to address the psychosocial problems associated with reduction in quality of life of patients affected with glaucoma.

\section{References}

1. Sommer A, Doyne L. Glaucoma facts and fancies. Ophthalmology, 2006, 16:295-301.

2. Green M, ed. Pediatric diagnosis, 18th ed. Philadelphia, WB Saunders, 2007:16-36.

3. Bohn L et al. Which patients are treated for glaucoma? An observational analysis. Journal of Glaucoma, 2007, 9(1):38-44.

4. Wilson M, Kosoko O, Cowan C. Progression of visual field loss in untreated glaucoma patients and glaucoma suspects in St. Lucia, West Indies. American Journal of Ophthalmology, 2002, 134:399-405.

5. Belal S. Post operative self-care guide for patients with intraocular surgery [MSc thesis]. Cairo, Department of Medical Surgical, Faculty of Nursing, Ain Shams University, 2006.

6. Danesh M. Food supplementation and eye exercises are decreasing IOP. Journal of Glaucoma, 2009, 18:563-566.

7. Neuberger J. The educated patient with glaucoma: new challenges for the medical profession. Journal of Internal Medicine, 2000, 74:6-10.

8. Tsai T, Robin AL, Smith JP. An evaluation of how glaucoma pa tients use topical medications: a pilot study. Transactions of the American Ophthalmological Society, 2007, 105:29-35.

9. Dawn A, Freedman, S, Enyedi L. Patients' expectations regarding their eye care; interview results. American Journal of Ophthalmology, 2007, 136:796-785.

10. Cheng TL, et al. Expectations, goals and perceived effectiveness of child health supervision: a study of adolescents in pediatric practice. Clinical Pediatircs, 2007, 35:1129-1137.

11. Marion M, Tumully R. Prevalence and incidence statistics for glaucoma in Northern Africa. American Journal of Nursing, 2007, 83:752-756.

12. Farid M. Fundamentals of pediatrics. Cairo, Department of Pediatrics, Faculty of Medicine, Ain Shams University, 2009:97-99.

13. Alexander MF, ed. Nursing practice: hospital and home, 2nd ed. London, Churchill Livingstone, 2003:500-507.
14. Watksinon S, Seewoodhaky R. Administering eye medications, Nursing Standard, 2009, 22(18):42-48.

15. El-Hawashy R et al. Textbook of basic nursing, 9th ed. New York, JB Lippincott, 2005:187-200.

16. Abdel-Hamid S, El-Nail E. Children manifest anxiety scale. Cairo, Dar El Nahda El-Masryia, 1991.

17. Reynolds CR, Richmond BO. What I think and feel: a revised measure of children's manifest anxiety. Journal of Abnormal Child Psychology, 1978, 6(2):271-280.

18. Abdel-Fattah G. Children depression inventory. Cairo, Dar EI Nahda El-Masryia, 1988.

19. El-Dosoki M. Self esteem-inventory. Cairo, Dar El Nahda ElMasryia, 1987.

20. Dawn AG, Santiago-Turla C, Lee PP. Patient expectations regarding eye care: development and results of the Eye Care Expectations Survey (ECES). Archives of Ophthalmology, 2003, 121(36):762-768.

21. Ahmad M. Assessment of patients needs: Nurses role in caring children with ophthalmological diseases [MSc thesis]. Cairo, Faculty of Nursing, Ain Shams University, 2007.

22. Kang $J$ et al. Dietary fat consumption and primary openangle glaucoma. American Journal of Clinical Nutrition, 2007, 79:755-764.

23. Murtadha A. Neuroprotection in glaucoma [MSc thesis]. Cairo, Department of Ophthalmology, Faculty of Medicine, University of Cairo, 2007.

24. Gail P. Eye drops installation: glaucoma. Nursing Times, 2009, 21:51-55.

25. Marsden J, Show M. Correct administration of topical eye treatment. Nursing Standard, 2009, 17(30):42-44.

26. Aumar R. Review of primary congenital glaucoma [MSc thesis]. Cairo, Department of Ophthalmology, Faculty of Medicine, Ain Shams University, 2007. 
27. Uenishi Y et al. Quality of life of elderly Japanese patients with glaucoma. International Journal of Nursing Practice, 2007, 9:28-35.

28. Eldar R. Quality of care in ophthalmology. Ophthalmology, 2004, 45(3):350-353.

29. Thompson T. Causes and signs of anxiety and depression in children with glaucoma. Ophthalmology, 2007, 27:335-336.
30. Marple L et al. Concerns and expectations in patients presenting with physically complaints: frequency of physician perceptions and actions and 2 week outcome. Archives of Internal Medicine, 2007, 157:1482-1488.

31. Dondona R. et al. Awareness of eye diseases in an urban population in southern India. Bulletin of the World Health Organization, 2001, 79:96-102.

\section{Control and prevention of blindness in the Region}

Available data indicates that about 37 million people are visually impaired in the Region, of whom 5.3 million people are blind; 15 million suffer from low vision and 16 million from refractive errors. The burden of blindness lies mainly in countries with large populations and poor communities, causing a huge economic burden to families and communities; $80 \%$ of these cases are avoidable, treatable or curable with simple cost-effective interventions.

The Control and Prevention of Blindness programme was established in 2001 to assist Member States in the World Health Organization's Eastern Mediterranean Region to develop comprehensive eye care and prevention of blindness programme at the national and subnational level in collaboration with partners. Our mission is to eliminate the main causes of avoidable blindness by the year 2020 in the Region.

Further information about the work of the WHO Regional Office for the prevention of avoidable blindness can be found at: http://www.emro.who.int/cpb/ 